\title{
BMJ Open Effect of food insecurity on mental health of patients with tuberculosis in Southwest Ethiopia: a prospective cohort study
}

\author{
Matiwos Soboka (D) , ${ }^{1,2}$ Markos Tesfaye, ${ }^{1,3}$ Kristina Adorjan, ${ }^{1,4,5}$ Wolfgang Krahl, ${ }^{1,6}$ \\ Elias Tesfaye, ${ }^{2}$ Yimenu Yitayih (1) , ${ }^{2}$ Ralf Strobl, ${ }^{7,8}$ Eva Grill ${ }^{1,7,8}$
}

To cite: Soboka M, Tesfaye M, Adorjan $\mathrm{K}$, et al. Effect of food insecurity on mental health of patients with tuberculosis in Southwest Ethiopia: a prospective cohort study. BMJ Open 2021;11:e045434. doi:10.1136/ bmjopen-2020-045434

- Prepublication history for this paper is available online. To view these files, please visit the journal online (http://dx.doi org/10.1136/bmjopen-2020045434).

Received 15 0ctober 2020 Accepted 29 August 2021
Check for updates

(C) Author(s) (or their employer(s)) 2021. Re-use permitted under CC BY-NC. No commercial re-use. See rights and permissions. Published by BMJ.

For numbered affiliations see end of article.

Correspondence to

Matiwos Soboka;

matiwos2004@yahoo.com

\section{ABSTRACT}

Objective The objective of this study is to investigate the effect of food insecurity on the mental health of patients with tuberculosis (TB) in Ethiopia.

Design A prospective cohort study.

Setting Health centres and hospitals located in Jimma zone, Southwest Ethiopia.

Participants Patients with TB who had recently been diagnosed with TB and started directly observed treatment in the selected 26 health institutions from 0ctober 2017 to October 2018. A total of 268 patients were followed for 6 months and data were collected at recruitment and two follow-up visits (at 2 and 6 months). Patients with multidrug-resistant TB were not included in the study. Main outcome measures Mental distress was measured by the Self-Reporting Questionnaire-20 while food insecurity was assessed by using the Household Food Insecurity Access Scale.

Results A total of 268 patients were recruited and there was no lost to follow-up. The prevalence of food insecurity at baseline, first and second follow-up was $49.3 \%, 45.9 \%$ and $39.6 \%$, respectively. Of these, $28.0 \%$ of them reported severe food insecurity at baseline which declined to $23.5 \%$ at the end of the sixth month. Likewise, the prevalence of mental distress at baseline was $61.2 \%$ but declined to $22.0 \%$ at the second follow-up. At baseline, $77.3 \%$ of patients with mental distress reported severe food insecurity but declined to $46.0 \%$ at second follow-up. In the final model, severe food insecurity (OR 4.7, 95\% Cl 2.4 to 9.4) and being a government employee (adjusted odds ratio (aOR) $0.3,95 \% \mathrm{Cl} 0.1$ to 0.9 ) were associated with mental distress.

Conclusion In this study, food insecurity was associated with mental distress over the course of follow-up. Likewise, there is a high prevalence of food insecurity and mental distress among patients with TB on treatment. Therefore, early assessment and interventions for food insecurity may improve the mental health of patients with TB on treatment.

\section{INTRODUCTION}

Food insecurity is 'a state of limited or uncertain availability of nutritionally adequate and safe foods, or lack of access to food of sufficient quality and quantity or limited or
Strengths and limitations of this study

- This is the first study recruited participants from primary care facilities in rural and urban settings, and assessing the effect of food insecurity on the mental health of patients with tuberculosis (TB).

- The consideration of several known confounding variables in the data analysis makes our results robust.

- The limitation of this study is that it did not include hospitalised patients, patients on retreatment and patients with multidrug-resistant (MDR)-TB.

- Patients with MDR-TB and hospitalised patients with TB may have higher depression and anxiety and their exclusion might have led to underestimated prevalence of mental distress.

uncertain ability to acquire acceptable foods in socially acceptable ways'. ${ }^{2}$ Globally, nearly 2 billion people suffered from moderate or severe food insecurity in 2019. ${ }^{1}$ This is a great challenge for the second sustainable development goal which aims for zero hunger by 2030. ${ }^{1}$ In Africa, food insecurity is increasing with about one-fifth of the population experiencing malnutrition. ${ }^{1}$ Approximately, 25\% of the Ethiopian population experienced food insecurity in $2016^{2}$ mainly because of drought. ${ }^{3}$ Studies showed that food insecurity is associated with the occurrence of tuberculosis (TB), worse TB treatment outcomes ${ }^{45}$ and poorer mental health among patients with TB. ${ }^{6}$

Mental distress is a type of mental health problem that includes symptoms of depression, anxiety and somatic complaints, which may not fall into standard diagnostic criteria. ${ }^{78}$ In Ethiopia, up to $67.6 \%$ of patients with TB had symptoms of mental distress. ${ }^{9} 10$ Food insecurity increases mental distress by generating uncertainty over the ability to maintain food supplies, or to acquire sufficient food 
in the future, so it provokes a stress response that may contribute to anxiety and depression. ${ }^{11}{ }^{12}$ Mental distress is associated with poorer adherence to anti-TB medications, ${ }^{13}$ and TB treatment outcomes. ${ }^{4}$ Also, food insecurity has a huge impact on treatment outcomes because those who have food insecurity at high risk of malnutrition and medication side effects. ${ }^{6}$

Even though food insecurity may potentially contribute to the occurrence of mental distress and affect treatment outcomes among patients with TB in Ethiopia, the link between food insecurity and mental distress was not adequately investigated. So, it is poorly understood how food insecurity affects mental health of patients with TB. Furthermore, most of the studies done in this region were cross-sectional design, and thus, they did not investigate the direction of the association between food insecurity and mental distress. Having the information regarding the association between food insecurity and mental distress is important for planning intervention strategies to improve the mental health of patients with $\mathrm{TB}$ and its complications. Therefore, the objective of this study was to assess the effect of food insecurity on mental health among patients with TB in Southwest Ethiopia.

\section{METHODS}

\section{Study area and design}

A prospective cohort study was conducted among patients with TB in Jimma Zone, Southwest Ethiopia. Jimma Zone has more than three million inhabitants, about $3 \%$ of the total population of Ethiopia. Typically, in Ethiopia TB care is mainly provided by local decentralised health centres to increase take-up of therapy and to monitor directly observed treatment (DOT). At the time of data collection, 91 out of 112 Jimma Zone health centres were providing services for patients with TB. Likewise, there were dedicated TB treatment services at all (four) hospitals. Patients were recruited from four hospitals and 22 randomly selected health centres of Jimma Zone. Twenty health centres and three hospitals were situated in rural areas whereas the remaining one hospital and two health centres were located in Jimma town. The study was conducted for 1 year from October 2017 to October 2018.

\section{Sample size assumption and sampling procedure}

We included all patients who had recently been diagnosed with TB and had started DOT in the selected health centres and hospitals. Only patients who had started TB treatment within less than 4 weeks before inclusion and were not planning to transfer to other health institutions were included in the study. Patients younger than 18 years, patients infected with multidrug-resistant (MDR) TB strains, and patients who were hospitalised during data collection were excluded from the study. The sample for this study was drawn from a cohort registered as $m$ /

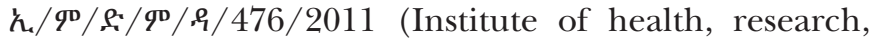
and postgraduate director 476/2011). Patients who consented to participate in the study were consecutively recruited. One hundred and thirty-two food insecure and 136 food secure patients with TB were followed up for 6 months. Detailed information regarding the study was given by trained data collectors to each patient before written informed consent was obtained.

\section{Data collection procedure}

Before data collection, the questionnaires were pretested on a sample (5\% of the total sample) of patients with patients with $\mathrm{TB}$ who had been on treatment at one health centre in Agaro to check whether the questions work as intended or understood by patients. Fourteen patients from the pretest were not included in the final analysis of the data. Patients were interviewed on three occasions namely, baseline (starting treatment), first follow-up (after 2 months) and second follow-up (at the end of the sixth month). Recruitment of patients and data collection were carried out by health professionals who were working in the TB clinic and specifically trained on the questionnaires, supervised by trained district focal persons.

\section{MEASURES}

\section{Outcome variable}

Mental distress

The Self-Reporting Questionnaire-20 (SRQ-20) was used to assess mental distress. Examples of the items are sleeplessness, tiredness, irritability, suicidal ideation, poor memory, difficulty in concentrating and somatic complaints. SRQ-20 has been adapted and validated in the Ethiopian context. This is a 20-item questionnaire with a maximum total score of 20 where a total score of below 7 indicates the absence of mental distress, while values of and above indicate mental distress. ${ }^{14}$

\section{Independent variables}

Food insecurity was assessed by using the Household Food Insecurity Access Scale to determine whether the respondent has experienced any of the indicators of food insecurity in the previous month. No food insecurity is present if none of the items apply. Mild food insecurity is defined as if the respondent endorsed any of the questions 1, 2, 3 and/or 4 but not the questions 5-9. Moderate food insecurity is defined as if the respondent has endorsed questions 5 and/or 6 but not the items 7-9, and 'severe food insecurity' if the respondent has endorsed questions 7,8 and/or $9 .{ }^{15}$ The tool has been widely used among people living with HIV (PLHIV) in Ethiopia. ${ }^{16}$

\section{Alcohol use disorders}

The alcohol use disorder identification test (AUDIT) was used to collect data on alcohol use disorders (AUDs). ${ }^{17}$ The AUDIT was evaluated over two decades and provides an accurate measure of the risk of AUDs across gender, age and cultures. With a cut-off score of 8 or more, the sensitivity and specificity of AUDIT for AUDs were 0.90 and 0.80 , respectively. ${ }^{18}$ AUDIT was used in the Ethiopian 
context and questions number two and three regarding standard drinks were adapted to a more locally appropriate question. Local alcohol drinks, for example, arake, tela and teji were first converted from local measurements to millilitres. Then the measured alcohol was converted into a standard drink by calculating the mass and volume of the alcohol. Similarly, local beer (bottles and glasses), draft and wine were converted to standard drinks based on their alcohol content. ${ }^{19}$

\section{Khat use}

Khat use was assessed by a self-reported questionnaire. Since there is no standardised questionnaire for khat use, patterns and reasons for khat use were assessed by using a structured questionnaire that was developed after reviewing the literature. Any consumption of khat during the last month was considered as current khat use.

\section{Sociodemographic variables}

Age, sex, marital status, level of education, religion, ethnicity, income, household size, occupation, place of residence and living conditions were assessed using a structured questionnaire. Income was categorised considering that the minimum monthly wage for employees of a governmental organisation in Ethiopia was Br1214 $(€ 36.67) .{ }^{20}$ Then the monthly income of each patient was multiplied by 12 months to obtain the annual income, and we used a cut-off Br14568 (€439.98).

\section{Social support}

The Oslo Social Support Scale (The Oslo 3 items) was used to collect data on the strength of social support. The Oslo-3 total score 3-8 indicates poor social support, 9-11 indicates moderate social support and 12-14 indicate strong social support. ${ }^{21}$ The scale has been widely used among patients with TB in Ethiopia. ${ }^{22}$ Social support was assessed at baseline, second month (at first follow-up), and 6 months (at the completion of anti-TB treatment or second follow-up).

\section{Comorbidities}

Data related to comorbidities such as HIV, previous mental illness, hypertension and diabetes mellitus were collected from patients' charts.

\section{Data analysis}

Participants' characteristics and study variables were described using descriptive statistics. The missing values were excluded from the analysis. A generalised linear mixed model was used to examine the effect of food insecurity over 6 months. All time points for food insecurity and mental distress were included in the analysis. An intercept only model was used to investigate mental distress over time (model 0 ) without adding other variables; model 1 investigated the association between food insecurity and mental distress without including other variables. Model 2 investigated the association between food insecurity and mental distress after controlling for substance use. Model 3 (full model) investigated the association between and food insecurity on mental distress after adjusting for the full set of a covariate. Model fitness was examined with the Bayesian Information Criterion. Data were analysed using R (V.1.2.1335).

\section{Role of the funding source}

The funder of the study had no role in study design, data collection, data analysis, data interpretation, or writing of the report. The corresponding author had full access to all the data in the study and had final responsibility for the decision to submit for publication.

\section{Patient and public involvement}

Patients were not involved in the development of the research questions, study design, interpretation of results or writing of the manuscript.

\section{RESULTS}

\section{Sociodemographic and clinical characteristic}

In this study, a total of 268 patients (mean age $=32.4$, $\mathrm{SD}=14.4$, range $=18-80$ years, and $60.1 \%$ male) were recruited and followed over 6 months. There was no lost to follow-up. Out of the total patients, 132 (49.3\%) patients with TB had food insecurity, while 136 (50.7\%) of them had food security at baseline (see table 1). Out of the total participants, $40.3 \% \quad(n=108), 32.5 \% \quad(n=87)$ and $27.2 \%(\mathrm{n}=73)$ were diagnosed as smear-positive, smear-negative and extrapulmonary $\mathrm{TB}$, respectively. At baseline, $3.7 \%(n=10)$ patients were diagnosed with HIV, and $7.1 \%(\mathrm{n}=19)$ with other comorbidities. There were 22 missing data of annual income which we excluded from the analysis.

\section{The magnitude of food insecurity}

The prevalence of food insecurity at baseline, second month and sixth month was $49.3 \% \quad(\mathrm{n}=132), 45.9 \%$ $(n=123)$ and $39.6 \%(n=106)$, respectively. Out of patients with food insecurity, $21.3 \%(n=57)$ and $28.0 \%(n=75)$ of them had mild to moderate and severe food insecurity, respectively, at baseline. The prevalence of severe food insecurity at the second follow-up was $23.5 \%(\mathrm{n}=63)$. The prevalence of severe food insecurity among female participants was $31.8 \%, 34.6 \%$ and $22.4 \%$ at baseline, first and second follow-up, respectively. Also, the proportion of food insecurity at the end of the sixth month was higher among patients within the age group of 44-55 years compared with patients within the age group of 18-24 years $(37.0 \%$ vs $19.4 \%, \mathrm{p}=0.03)$. Moreover, the prevalence of severe food insecurity among daily labourers at baseline, first and second follow-up was $59.5 \%(\mathrm{n}=25), 57.1 \%$ $(\mathrm{n}=24), 50.0 \%(\mathrm{n}=21)$, respectively (see table 1$)$.

\section{The magnitude of mental distress}

The prevalence of mental distress at baseline, the second month and end of the sixth month was $61.2 \% \quad(\mathrm{n}=164)$, $38.1 \% \quad(n=10.2), 22.0 \% \quad(n=59)$, respectively. Out of patients with mental distress, the majority of them were in the age group of 55-64 years at baseline $(76.0 \%)$ and 
Table 1 Sociodemographic characteristics and food insecurity of tuberculosis patients in Southwest Ethiopia, 2017/2018 $(n=268)$

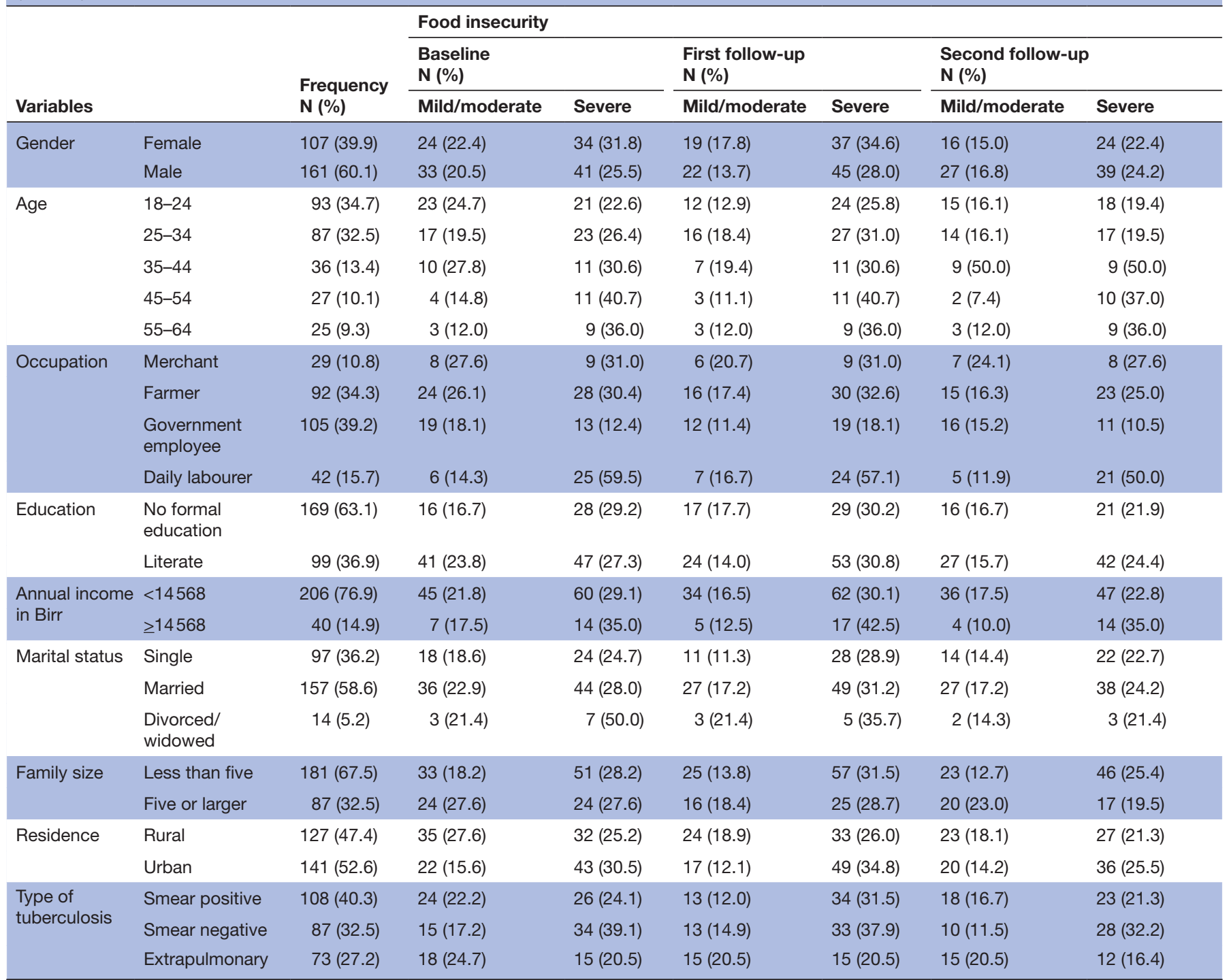

first follow-up (56.0) while it was $32.0 \%$ in the second follow-up. Of patients with mental distress, $71.4 \%$ were either divorced or widowed.

About three-fourths $(77.3 \%)$ of patients with severe food insecurity had mental distress at baseline, but it decreased to $64.6 \%$ and $46.0 \%$ in the second and sixth months, respectively. The prevalence of AUD among patients with mental distress was $62.1 \%, 44.2 \%$ and $18.6 \%$ at baseline, first follow-up and second follow-up, respectively, while $65.7 \%, 47.6,23.0 \%$ of them were using khat at baseline, first, and second follow-up, respectively (see table 2).

\section{Effect of food insecurity on mental distress}

The odds of having mental distress among patients with severe food insecurity was seven times higher than that of patients who had no food insecurity (OR 7.3, 95\% CI 3.7 to 14.2). After adding alcohol and khat use disorder into model 2, there was no change in the association between severe food insecurity and mental distress (adjusted odds ratio (aOR) $7.0,95 \%$ CI 3.6 to 13.7 ).

After adjusting for potential confounder using a generalised linear mixed model, severe food insecurity (OR $4.7,95 \%$ CI 2.4 to 9.4 ) and being a government employee (aOR $0.3,95 \%$ CI 0.1 to 0.9 ) were associated with mental distress. Government employees had a $70 \%$ lower likelihood of having mental distress compared with the local trader (see table 3).

\section{DISCUSSION}

To our knowledge, this is the first study that assessed the relationship between food insecurity and mental distress among patients with TB. In this study, we found: (1) a high prevalence of mental distress among patients with food insecurity, (2) severe food insecurity was associated with mental distress independent of sociodemographic 
Table 2 Mental distress at the three time points among patients with tuberculosis in Southwest Ethiopia, 2017/2018 ( $n=268)$

\begin{tabular}{|c|c|c|c|c|c|c|c|}
\hline \multirow[b]{3}{*}{ Variables } & & \multicolumn{6}{|c|}{ Mental distress } \\
\hline & & \multicolumn{2}{|l|}{ Baseline } & \multicolumn{2}{|c|}{ First follow-up } & \multicolumn{2}{|c|}{ Second follow-up } \\
\hline & & $\begin{array}{l}\text { Yes } \\
\text { N (\%) }\end{array}$ & $\begin{array}{l}\text { No } \\
\text { N (\%) }\end{array}$ & $\begin{array}{l}\text { Yes } \\
\text { N (\%) }\end{array}$ & $\begin{array}{l}\text { No } \\
\text { N (\%) }\end{array}$ & $\begin{array}{l}\text { Yes } \\
\text { N (\%) }\end{array}$ & $\begin{array}{l}\text { No } \\
\text { N (\%) }\end{array}$ \\
\hline \multirow[t]{2}{*}{ Gender } & Male & $104(64.6)$ & 57 (35.4) & $66(41.0)$ & 95 (59.0) & $45(28.0)$ & $116(72.0)$ \\
\hline & Female & $60(56.1)$ & 47 (43.9) & $36(33.6)$ & $71(66.4)$ & $14(13.1)$ & 93 (86.9) \\
\hline \multirow{3}{*}{ Age } & $35-44$ & $26(72.2)$ & $10(27.8)$ & $16(44.4)$ & $20(55.6)$ & $10(27.8)$ & $26(72.2)$ \\
\hline & $45-54$ & $20(74.1)$ & $7(25.9)$ & $13(48.1)$ & $14(51.9)$ & $6(22.2)$ & $21(77.8)$ \\
\hline & $55-64$ & $19(76.0)$ & $6(24.0)$ & $14(56.0)$ & $11(44.0)$ & $8(32.0)$ & $17(68.0)$ \\
\hline Occupation & Merchant & $24(82.8)$ & 5 (17.2) & $12(41.4)$ & $17(58.6)$ & $7(24.1)$ & $22(75.9)$ \\
\hline \multirow[t]{2}{*}{ Education } & No formal education & 55 (57.3) & $41(42.7)$ & $35(36.5)$ & $61(63.5)$ & $21(21.9)$ & $75(78.1)$ \\
\hline & Educated & $109(63.4)$ & $63(36.6)$ & $67(39.0)$ & $105(61.0)$ & $38(22.1)$ & $134(77.9)$ \\
\hline \multirow[t]{3}{*}{ Marital status } & Single & $48(49.5)$ & $49(50.5)$ & $26(26.8)$ & 71 (73.2) & 20 (20.6) & $77(79.4)$ \\
\hline & Married & $106(67.5)$ & $51(32.5)$ & 71 (45.2) & $86(54.8)$ & 35 (22.3) & $122(77.7)$ \\
\hline & Divorced/widow & $10(71.4)$ & 4 (28.6) & $5(35.7)$ & $9(64.3)$ & 4 (28.6) & $10(71.4)$ \\
\hline \multirow[t]{2}{*}{ Family size } & Less than five & $103(56.9)$ & $78(43.1)$ & $74(40.9)$ & $107(59.1)$ & $44(24.3)$ & $137(75.7)$ \\
\hline & Five and more & $61(70.1)$ & 26 (29.9) & 28 (32.2) & $59(67.8)$ & 15 (17.2) & $72(82.8)$ \\
\hline Residence & Rural & $93(73.2)$ & $34(26.8)$ & $48(37.8)$ & $79(62.2)$ & $24(18.9)$ & $103(81.1)$ \\
\hline Social support & Good & 38 (61.3) & $24(38.7)$ & $20(27.8)$ & $52(72.2)$ & $3(5.6)$ & $51(94.4)$ \\
\hline \multirow[t]{3}{*}{ Food insecurity } & No & $69(50.7)$ & $67(49.3)$ & $36(24.8)$ & 109 (75.2) & $18(11.1)$ & $144(88.9)$ \\
\hline & Mild/moderate & 37 (64.9) & $20(35.1)$ & $13(31.7)$ & $28(68.3)$ & $12(27.9)$ & $31(72.1)$ \\
\hline & Severe & 58 (77.3) & $17(22.7)$ & $53(64.6)$ & $29(35.4)$ & $29(46.0)$ & $34(54.0)$ \\
\hline \multirow[t]{2}{*}{ AUD } & No & $146(61.1)$ & 93 (38.9) & $83(36.9)$ & $142(63.1)$ & $51(22.7)$ & $174(77.3)$ \\
\hline & Yes & $18(62.1)$ & 11 (37.9) & 19 (44.2) & $24(55.8)$ & 8 (18.6) & $35(81.4)$ \\
\hline \multirow[t]{2}{*}{ Khat use } & No & 95 (58.3) & $68(41.7)$ & $52(31.9)$ & $111(68.1)$ & $36(21.4)$ & $132(78.6)$ \\
\hline & Yes & $69(65.7)$ & 36 (34.3) & $50(47.6)$ & $55(52.4)$ & $23(23.0)$ & $77(77.0)$ \\
\hline
\end{tabular}

AUD, alcohol use disorder.

factors, substance use, social support and type of TB diagnosis.

The baseline prevalence of food insecurity found in this study $(49.3 \%)$ was lower than the finding of a study done in Surabaya, Indonesia (64\%). ${ }^{23}$ The baseline prevalence of food insecurity found in this study falls within the range of prevalence reported from two studies done among PLHIV in Southwest Ethiopia $(38.7 \%$ and $63.0 \%) .{ }^{16} 24$
In this study, higher proportions of female patients were found to have food insecurity at baseline $(54.2 \%)$ and first follow-up $(52.3 \%)$. This might be due to women's limited economic, educational and employment opportunities and because they are more involved in unpaid work such as childcare and domestic activities than men particularly in a low-income country like Ethiopia. ${ }^{25-27}$ So, further study is needed to address the gender disparity in terms of 
Table 3 Factors affecting mental distress among patients with TB in Southwest Ethiopia 2017/2018 (n=268)

\begin{tabular}{|c|c|c|c|c|c|c|c|c|c|c|}
\hline \multirow[b]{3}{*}{ Variables } & & \multicolumn{3}{|c|}{ Model 1} & \multicolumn{3}{|c|}{ Model 2} & \multicolumn{3}{|c|}{ Full model } \\
\hline & & \multirow[b]{2}{*}{ aOR } & \multicolumn{2}{|l|}{$95 \% \mathrm{Cl}$} & \multirow[b]{2}{*}{ aOR } & \multicolumn{2}{|l|}{$95 \% \mathrm{Cl}$} & \multirow[b]{2}{*}{ aOR } & \multicolumn{2}{|l|}{$95 \% \mathrm{Cl}$} \\
\hline & & & Lower & Upper & & Lower & Upper & & Lower & Upper \\
\hline \multirow{2}{*}{ Food insecurity } & Mild/moderate & 2.0 & 1.0 & 3.9 & 2.0 & 1.0 & 3.8 & 1.7 & 0.9 & 3.3 \\
\hline & Severe & 7.3 & 3.7 & 14.2 & 7.0 & 3.6 & 13.7 & 4.7 & 2.4 & 9.4 \\
\hline Gender & Male & - & - & - & - & - & - & 1.8 & 0.9 & 3.3 \\
\hline \multirow[t]{4}{*}{ Age } & $18-24$ & Ref & & & Ref & & & Ref & & \\
\hline & $25-34$ & - & - & - & - & - & - & 0.9 & 0.5 & 2.1 \\
\hline & $35-44$ & - & - & - & - & - & - & 1.5 & 0.5 & 4.4 \\
\hline & $45-54$ & - & - & - & - & - & - & 1.2 & 0.4 & 3.9 \\
\hline \multirow{3}{*}{ Occupation } & Farmer & - & - & - & - & - & - & 0.9 & 0.3 & 2.6 \\
\hline & $\begin{array}{l}\text { Government } \\
\text { employee }\end{array}$ & - & - & - & - & - & - & 0.3 & 0.1 & 0.9 \\
\hline & Daily labourer & - & - & - & - & - & - & 0.8 & 0.3 & 2.8 \\
\hline \multirow[t]{2}{*}{ Annual income } & $<14568$ Eth Birr & Ref & . & & Ref & & & Ref & & \\
\hline & $\geq 14568$ & - & - & - & - & - & - & 1.9 & 0.8 & 4.3 \\
\hline \multirow[t]{3}{*}{ Marital status } & Married & & & & Ref & & & Ref & & \\
\hline & Single & - & - & - & - & - & - & 0.8 & 0.4 & 1.7 \\
\hline & $\begin{array}{l}\text { Widowed/ } \\
\text { divorced }\end{array}$ & - & - & - & - & - & - & 0.9 & 0.2 & 3.5 \\
\hline \multirow[t]{2}{*}{ Khat use } & No & Ref & & & Ref & & & & & \\
\hline & Yes & - & - & - & 1.5 & 0.9 & 2.6 & 1.1 & 0.6 & 1.9 \\
\hline \multirow[t]{3}{*}{ Social support } & Good & Ref & & & Ref & & & Ref & & \\
\hline & Moderate & - & - & - & - & - & - & 1.3 & 0.7 & 2.4 \\
\hline & Poor & - & - & - & - & - & - & 1.2 & 0.6 & 2.2 \\
\hline $\mathrm{BIC}$ & & 886.6 & & & 896.4 & & & 955.3 & & \\
\hline
\end{tabular}

aOR, Adjusted Odds Ratio; AUD, alcohol use disorder; BIC, Bayesian information criterion; Ref, Reference; TB, tuberculosis.

food insecurity and treatment outcomes among patients with TB in Ethiopia and other low-income countries. In this study, more than half of daily labourers reported food insecurity at baseline $(59.5 \%)$, first $(57.1 \%)$ and second $(50.0 \%)$ follow-up. This may be due to daily labourers have low income and as a result, face difficulties in accessing adequate food. Studies showed that low income was associated with food insecurity. ${ }^{28} 29$

In this study, the prevalence of mental distress was decreasing over 6 months from $61.2 \%$ at baseline to $22.0 \%$ at the second follow-up. This is consistent with other studies done on similar populations in Ethiopia ${ }^{10}$ and South Africa. ${ }^{30}$ This might be due to patients with TB experience severe symptoms of the disease in the first month of treatment initiation which may overlap with the symptoms of mental distress but as patients get improvement from TB, symptoms of mental distress may also decline. Also, since SRQ-20 contains several physical symptoms that overlap with the symptoms of TB, the improvement of TB symptoms such as fatigue, loss of appetite throughout anti-TB treatment may account for the reduction in the level of mental distress. However, the baseline prevalence of mental distress found in this study $(61.2 \%)$ was greater than the finding of a study 
done in Angola $(44.4 \%)^{31}$ and South Africa (34.1\%). ${ }^{30}$ The difference might be due to the tool used to assess mental distress (SRQ-20 vs Hospital Anxiety and Depression Scale, and K-10). For example, K-10 has nine items of psychological symptoms and only one physical item, so little overlap with TB symptoms compared with SRQ-20. The prevalence of mental distress at the first $(38.1 \%)$ and second $(22.0 \%)$ follow-up found in this study was in line with the studies conducted in Huambo hospital, Angola $(44.4 \%)^{32}$ and South Africa $(21.8 \%)^{30} 33$ but lower than the finding of studies conducted in a similar population in Dire Dawa and Harar cities $(63.3 \%)^{9}$ and Addis Ababa Ethiopia $(48.5 \%) .^{10}$

In this study, severe food insecurity was associated with mental distress independent of other covariates which are in line with previous studies done in similar populations in Zambia and South Africa. ${ }^{34-36}$ Also, it is in line with a community-based study conducted in Rural Tigray and SNNP (Southern Nations, Nationalities, and Peoples) Regions, Ethiopia. ${ }^{37}$ This may be due to uncertainty to have adequate food could lead to chronic stress that affects the mental health of the patients. ${ }^{35}$

\section{LIMITATIONS}

The limitation of this study is that it did not include hospitalised patients, patients on retreatment and patients with MDR-TB, therefore, the results cannot be generalised for these patients. Patients with MDR-TB and hospitalised patients with TB may have higher depression and anxiety and their exclusion might have led to an underestimated prevalence of mental distress.

Patients with MDR-TB are under special treatment and surveillance so that including this group of patients might have biased the results. Moreover, SRQ-20 is not a goldstandard to measure mental disorders. So, TB related physical symptoms might overlap with SRQ-20 and led to the overestimate of mental distress.

\section{STRENGTHS}

Some strengths of this study are: the recruitment of participants from primary care facilities in rural and urban settings, and the consideration of several known confounding variables in the data analysis make our results robust. Also, the good surveillance system and presence of follow-up make the data collection highly reliable.

\section{CONCLUSIONS}

In this study, we have found a high prevalence of food insecurity and mental distress among patients with TB. Likewise, food insecurity associated with mental distress independent of other covariates. This implies that many patients with $\mathrm{TB}$ in Southwest Ethiopia are suffering from both mental health problems and lack of adequate food both of which might adversely affect treatment outcomes. Therefore, this finding would be an input for TB programmes so that effective interventions for mental distress and food insecurity are integrated into the care of patients with TB. Future studies need to evaluate the effectiveness of interventions for food insecurity in reducing mental distress in patients with TB.

\section{Author affiliations}

${ }^{1}$ Center for International Health, Ludwig Maximilian University, Munich, Germany ${ }^{2}$ Department of Psychiatry, Medical Faculty, Jimma University, Jimma, Ethiopia ${ }^{3}$ Department of Psychiatry, St. Paul's Hospital Millennium Medical College, Addis Ababa, Ethiopia

${ }^{4}$ Institute of Psychiatric Phenomics and Genomics (IPPG), University Hospital, LMU, Munich, Germany

${ }^{5}$ Department of Psychiatry and Psychotherapy, LMU Munich, Munich, Germany ${ }^{6}$ Department of Forensic Psychiatry, Isar Amper Klinikum, Munich, Germany ${ }^{7}$ German Center for Vertigo and Balance Disorders, University Hospital LMU Muenchen, Munich, Germany

${ }^{8}$ Institute for Medical Information Processing, Biometry and Epidemiology, Ludwig Maximilians University Muenchen, Munich, Germany

Acknowledgements We are grateful to the study participants for compromising their time to participate in the study. Our gratitude is extended to Jimma University for funding the project. We are also grateful to IPPG for funding part of the project. Our gratitude extended to Dr. Michael Odenwald, who contributed money from his pocket to support the project.

Contributors MS contributed to the conceptualisation, design, statistical analysis, and manuscript preparation. MT, KA, WK, ET, YY, RS and EG contributed to the design, analysis, and review of the manuscript.

Funding The study was funded by Jimma University Institute of Health with the grant number of IHRPGC 1095/2017, Institute of Psychiatric Phenomics, and Genomics (IPPG) with the grant number of 15106202/2018, and individual throughout data collection. The funders had no role in this study including interpretation and preparation of the manuscript.

\section{Competing interests None declared.}

Patient and public involvement Patients and/or the public were not involved in the design, or conduct, or reporting, or dissemination plans of this research.

Patient consent for publication Not required.

Ethics approval Ethical clearance was obtained from the Ethical Review Board of Jimma University(IHRPGC/765/2017) and LMU (Nr: 18-017). The study was explained in detail and written informed consent was obtained from each participant. The anonymity of the study participants was kept at all stages of data processing and write-up of the manuscript.

Provenance and peer review Not commissioned; externally peer reviewed.

Data availability statement Data may be obtained from a third party and are not publicly available. All data relevant to the study are included in the article. It will be available upon official request from interested individuals or organisations.

Open access This is an open access article distributed in accordance with the Creative Commons Attribution Non Commercial (CC BY-NC 4.0) license, which permits others to distribute, remix, adapt, build upon this work non-commercially, and license their derivative works on different terms, provided the original work is properly cited, appropriate credit is given, any changes made indicated, and the use is non-commercial. See: http://creativecommons.org/licenses/by-nc/4.0/.

\section{ORCID iDs}

Matiwos Soboka http://orcid.org/0000-0003-2820-0947

Yimenu Yitayih http://orcid.org/0000-0002-0300-394X

\section{REFERENCES}

1 FAO I, UNICEF, WFP, WHO. The state of food security and nutrition in the world 2019. In: Safeguarding against economic slowdowns and downturns. Rome: FAO, 2019.

2 World Food Programme. Comprehensive food security and vulnerability analysis (CFSVA); 2019. 
3 Abegaz KH. Determinants of food security: evidence from Ethiopian rural household survey (ERHS) using pooled cross-sectional study. Agric Food Secur 2017;6:70.

4 Cassidy DA, Ivers LC, Insecurity F. Food insecurity and tuberculosis: policy urgently needs to play catch-up. Ir Med J 2018;111:777.

5 Claros JM, de Pee S, Bloem MW. Adherence to HIV and TB care and treatment, the role of food security and nutrition. AIDS Behav 2014;18 Suppl 5:459-64.

6 Balinda IG, Sugrue DD, Ivers LC. More than malnutrition: a review of the relationship between food insecurity and tuberculosis. Open Forum Infect Dis 2019;6:ofz102.

7 Drapeau A, Marchand A, Beaulieu-Prévost D. Epidemiology of psychological distress. In: LAbate PL, ed. Mental illnesses understanding, prediction and control, 2012: 155-34.

8 Goldberg D. A bio-social model for common mental disorders. Acta Psychiatr Scand Suppl 1994;385:66-70.

9 Ayana TM, Roba KT, Mabalhin MO. Prevalence of psychological distress and associated factors among adult tuberculosis patients attending public health institutions in dire Dawa and Harar cities, eastern Ethiopia. BMC Public Health 2019;19:1392.

10 Tola HH, Shojaeizadeh D, Garmaroudi G, et al. Psychological distress and its effect on tuberculosis treatment outcomes in Ethiopia. Glob Health Action 2015;8:29019.

11 Kessler RC. The effects of stressful life events on depression. Annu Rev Psychol 1997;48:191-214.

12 Whitaker RC, Phillips SM, Orzol SM. Food insecurity and the risks of depression and anxiety in mothers and behavior problems in their preschool-aged children. Pediatrics 2006;118:e859-68.

13 Tola HH, Garmaroudi G, Shojaeizadeh D, et al. The effect of psychosocial factors and patients' perception of tuberculosis treatment non-adherence in Addis Ababa, Ethiopia. Ethiop $\mathrm{J}$ Health Sci 2017;27:447-58.

14 Hanlon C, Medhin G, Alem A, et al. Detecting perinatal common mental disorders in Ethiopia: validation of the self-reporting questionnaire and Edinburgh postnatal depression scale. J Affect Disord 2008;108:251-62.

15 Coates J, Swindale A, Bilinsky P. Household food insecurity access scale (HFIAS) for measurement of household food access: indicator guide (V. 3). Washington, D.C: FHI 360, FANTA, 2007.

16 Tesfaye M, Kaestel P, Olsen MF, et al. Food insecurity, mental health and quality of life among people living with HIV commencing antiretroviral treatment in Ethiopia: a cross-sectional study. Health Qual Life Outcomes 2016;14:37.

17 Babor TF, Higgins-Biddle JC, Saunders JB. The alcohol use disorders identification test guidelines for use in primary care. World Health Organization, 2001: 1-40.

18 Babor TF, Higgins-Biddle JC, Saunders JB. The alcohol use disorders identification test guidelines for use in primary care. 2nd Edn. World Health Organization, 2001

19 Soboka M, Tesfaye M, Feyissa GT, et al. Alcohol use disorders and associated factors among people living with HIV who are attending services in South West Ethiopia. BMC Res Notes 2014;7:828.

20 Average salary in Ethiopia 2019. Available: http://www.salaryexplorer. com/salary-survey.php?loc=69\&loctype=1 [Accessed $09 \mathrm{Jul} 2019$ ].
21 EU. Instrument manual: oslo-3 social support scale (OSS-3), 2006. Available: https://circabc.europa.eu/webdav/CircaBC/ESTAT/healthtf/ Library/ehis_wave_2/methodology_ehis/development/instruments/ Manual_OSS_3.pdf

22 Molla A, Mekuriaw B, Kerebih H. Depression and associated factors among patients with tuberculosis in Ethiopia: a cross-sectional study. Neuropsychiatr Dis Treat 2019;15:1887-93.

23 Susilaningrum D, Ulama BSS, Lathifah R. Mapping the factors affecting household food security of tuberculosis patients in coastal region of Surabaya. IOP Conf Ser Mater Sci Eng 2018;335:012053.

24 Tiyou A, Belachew T, Alemseged F, et al. Food insecurity and associated factors among HIV-infected individuals receiving highly active antiretroviral therapy in Jimma zone Southwest Ethiopia. Nutr J 2012;11:51.

25 Ferrant G, Thim A. Measuring women's economic empowerment: time use data and gender inequality. OECD Development Policy Papers, 2019.

26 International Monetary Fund. Women and the economy in Ethiopia 2018. Available: https://www.imf.org/ /media/Files/Publications/CR/ 2018/cr18355.ashx

27 Ivers LC, Cullen KA. Food insecurity: special considerations for women. Am J Clin Nutr 2011;94:1740S-4.

28 Ayiraveetil R, Sarkar S, Chinnakali P, et al. Household food insecurity among patients with pulmonary tuberculosis and its associated factors in South India: a cross-sectional analysis. BMJ Open 2020;10:e033798.

29 Loopstra R, Reeves A, Tarasuk V. The rise of hunger among lowincome households: an analysis of the risks of food insecurity between 2004 and 2016 in a population-based study of UK adults. J Epidemiol Community Health 2019;73:668-73.

30 Peltzer K. Decline of common mental disorders over time in public primary care tuberculosis patients in South Africa. Int J Psychiatry Med 2016;51:236-45.

31 Xavier PB, Peixoto B. Emotional distress in Angolan patients with several types of tuberculosis. Afr Health Sci 2015;15:378-84.

32 Paulo BX, Peixoto B. Emotional distress patients with several types of tuberculosis. A pilot study with patients from the Sanatorium hospital of Huambo. Int J Mycobacteriol 2016;5 Suppl 1:S58.

33 Theron G, Peter J, Zijenah L, et al. Psychological distress and its relationship with non-adherence to TB treatment: a multicentre study. BMC Infect Dis 2015;15:253.

34 Cole SM, Tembo G. The effect of food insecurity on mental health: panel evidence from rural Zambia. Soc Sci Med 2011;73:1071-9.

35 Jones AD. Food insecurity and mental health status: a global analysis of 149 countries. Am J Prev Med 2017;53:264-73.

36 Tomita A, Ramlall S, Naidu T, et al. Major depression and household food insecurity among individuals with multidrug-resistant tuberculosis (MDR-TB) in South Africa. Soc Psychiatry Psychiatr Epidemiol 2019;54:387-93.

37 Birhanu TT, Tadesse AW. Food insecurity and mental distress among mothers in rural Tigray and SNNP regions, Ethiopia. Psychiatry $J$ 2019;2019:1-6. 